\section{Tarantino, \\ Deleuze, \\ Baudrillard, tomates}

Fernando Mascarello

Mestrando em Comunicação / PUCRS
“Three tomatos are walking down the street, a poppa tomato, a momma tomato, and a little baby tomato. Thebaby tomato islagging behind the poppa and momma tomato. The poppa tomato gets mad, goes over to the baby tomato and stamps on him and says: - Catch up!"

A PIADINHA polissêmica contada por Mia a Vincent em Pulp Fiction narra a saga de um pequeno bebê tomate: ao ser instado pela ordem paterna de acompanhar o passo, é atingido evira suco. O tomatequevirou suco.

A diégesis, no entanto, não secontém no limite deseu enquadramento fílmico e, como metáfora, atinge o espectador. Manter o passo com a sucessão dos fotogramas tarantinianos é virar suco a cada seqüência. OK. Massigamosum pouco maiso percurso desta metáfora que não se detém: o espectador, na sala e fora dela, não é ele o homem pósmoderno? 0 ex-atendente devideo-locadora nos alerta para uma escolha polissêmica: manter o passo com o mundo (pós-moderno), ou virar suco.

Na comédia pastelão atiram-se tortas, em lugar de tomates. Versão antiga do suco. A celeuma em torno da obra do californiano diretortem-nosprogramadosurpresasasmais diversas. Pequenas guerras civis, grandes comoçõesnacionais. Debates, tapas, bofetões. Sem nos determos em versões tupiniquins, tomemos um exemplo (mais um) de um dos lados contendores:

“No sé si Tarantino es un psicópata, desde luego su personaje lo es... para dementes que se regodean en el sadismo... un país como Estados Unidos, con un índice de delincuencia exagerado, sólo le faltaba lo que ahora tiene que mostrar Tarantino ... una forma repulsiva de ver la violencia: domesticándola... un falsario ... el ejemplo supremo, máximo, de la más absoluta falta de comunicación. Pulp Fiction no cuenta nada, no dicenada, no habladenada, no expresa nada."(Delgado 1995: 94-102)

De outro lado, uma quase beatlemania, 
destino apropriado - em tempos de mídia para um psicopata em potencial (vide A ssassinos por $N$ atureza). Culto que se verifica em todos os níveis: grande público, cinefilia, tietagem levada a sério, crítica, etc. Mas seu avatar mais contundente talvez seja o da própriareelaboração artística; oquadroébem resumido por Ronson, do Indepen dent (citado em Dawson 1995: 207):

“... fui ver A mateur, deHal Hartley, no qual dois atiradores discutem as vantagens relativas do telefone celular antes de explodirem seu alvo. No dia seguinte, assisti às projeções definal desemestre da National Film School. De cada cinco filmesdosalunos, quatro incorporavam violentos tiroteios a uma trilha de pop hits iconoclásticos dos anos 70, doisterminavamcomtodosospersonagens disparando uns sobre os outros, e um tinha dois homens discutindo as idiossincrasias de The Brady Bunch antes de 'apagarem' sua vítima. Desde Cidadão Kane não aparecia um homem vindo deumarelativa obscuridadepara redefinir a arte do cinema."

Bem claro que a idolatria deforma e exagera. Os méritos, não o são de um só homem, nunca. A produção brasileira de "cine-violência", por exemplo, já era objeto da reflexão de Bernardet em 1994. A o americano, no entanto, coube o papel de aglutinar a atenção do imaginário internacional comrespeito ao que Jean-Claude propõechamar a "crueldadeirônica" decerta produção cinematográfica contemporânea.

Por outro lado, a polêmica envolvendo filmescujatemáticaéaviolêncianãoénenhuma novidade. Bonnieand Clyde(Arthur Penn, 1967) foi unanimemente atacado pela crítica quando do lançamento; logo a seguir, ganharia dez indicações para o Oscar. Algo semeIhante ao que se passou com M eu Ódio será tua H eran ça (TheW ild Bunch, Sam Peckinpah, 1969). A mbos são marcos no desenvolvimento da linguagem no que diz respeito à representação da violência. $\mathrm{O}$ sangue começava a jorrar, e feio. Mas estes filmes terminaram com a apreciação e estima relativamente geral. Fundamentalmente, porque seus diretores tinham o incansável (hoje) "comprometimento político" - aindaquealgo heterodoxo fossenaformaderomantismo revolucionário ou de al egoria da intervenção americana no sudeste asiático.

Pois Quentin só se compromete com trash e diversão. A própria palavra soa forte demais em setratando dele. M as apenas esta incorreção política dá conta do pastelão moralista a que temos assistido? Evidente que não. Outras entradas se fazem necessárias.

A sociedade pós-industrial éo reino da simulação midiática, e este é o universo diegético de Tarantino. São dois universos quesetangenciam. Para compreender o mestre-de-cerimônias do circo da violência, é mister invocar os dois grandes teóricos contemporâneos do simulacro: Gilles Deleuzee Jean Baudrillard.

No regime de simulação baudrillardiano, a mídia é responsável pela produção desenfreada de signos que já não guardam atrelamento com a realidade. O hiper-real assim produzido almeja ser mais real que a realidade quejá não é.

O pensador francêsorganizou ahistória da imagem em quatro estágios sucessivos. No primeiro, o signo "é o reflexo de uma realidade profunda" (1991: 13). A seguir, "mascara e deforma uma realidade profunda". Noterceiro, aimagem "mascaraa ausência deumarealidadeprofunda". E no último, ela já "não tem relação com qualquer realidade: ela é o seu próprio simulacro puro". Tarantino parecequerer inaugurar umanova etapa: seu cinema oferece um novo estágio, o da simulação do simulado, re-simulação do fabricado. O referente parasitado de seu signo não éa violência, masa representação dela quecriativamentevimosnos oferecendo. Fosse Tarantino brasileiro, sua imagem seria o simulacro de Gil Gomes.

É oportuno lembrar as considerações traçadas pelo norte-americano Fredric Jameson - embora dentro de uma ótica do político - sobrea problemática daestetização 
da real idade. Segundo sua teoria da visão no século XX (Jameson 1994), experimentamos recentemente a passagem de um momento foucaudiano a um outro pós-moderno do olhar. No primeiro, ainda era viável uma reflexividadeeauto-consciênciaarespeito da sociedade e de sua relação com a tecnologia da imagem midiática. No pós-moderno, porém, "a reflexividade como tal se submerge na pura superabundância de imagens como em um novo elemento no qual respiramos como se fosse natural" (1994: 120), criando um impasse.

O olhar tarantiniano propõe um novo estágio: busca ser reflexivo aravés de uma estetização do estético.

Voltemos ao campo da simulação. O parasitismo da imagem-simulacro do cineastasobreo representado dá-seatravésda paródia. Os formalistas russos falam dela como uma "decolagem" do texto parodiado através do desnudamento de seus mecanismos. $O$ mecanismo obsoleto não é descartado, mas repetido em um novo eincongruentecontexto, o que o caricatura e torna perceptível. A qui se iniciam as dificuldades na recepção do cinema deTarantino: o simulacro contemporâneo representado éum vírus assaz resistente ao desnudamento.

Q.T. sabe muito bem disso; esta a sua mágica e brincadeira. E eis então a origem de todo o embate crítico e acadêmico de que temos sido testemunhas: o simulacro tarantiniano do simulacro pós-moderno é cônscio deseuslimites. A inexpugnabilidade da imagem midiática revela-senalinguagem do diretor em todo o seu absurdo. 0 desnudamento da simulação representada não se efetua integralmente. Pelo contrário, estaciona perigosamente em uma terra de ninguém.

Melhor dizendo, o texto parodista confunde-se com o parodiado. É o carimbo no passaportedeTarantino para seu ingresso no país do sórdido, do psicopático, do reacionário.

O que o videolocador propõe então é o convívio com o jogo dos simulacros. Não podendovencêlo, une-seaele. Eéhoraassim de invocarmos Deleuze. Se ele não sobreviveu para pensar o cineasta norte-americano, seu aparato conceitual brinda-nos com a possibilidade de refletir sobre a sociedade pósmodernadeumamaneiramaispositivaqueo apocalíptico Baudrillard.

O simulacro de Deleuze é muito mais construtivo. A hiper-realidadeéo real. Como aponta Shaviro (1993: 5), "as aparências são instáveis, e devem ser continuamente reinterpretadas - não para descobrir averdade, mas precisamente porque não existe nenhumaverdadeprofunda". OndeBaudrillard propõe a "simulação como uma perda de real", Deleuzea indica como "uma produtiva intensificação da realidade".

Masseo hiper-real éo real, como tatuarmos nelea nossa marca? Desesperada enostal gicamente, sonhando com as utopias perdidas? Tarantino nos sugere uma produção alternativa de real simulado. A simulação midiática éinatacável. Pois ele, em facedisto, aceita o jogo e passa a usar de seus mesmos expedientes, produzindo, aqui e ali, um real com um viés diferenciado, para um público leitor disposto a buscá-lo.

Seguindo à risca as concepções bakhtinianas, o garoto do Tennessee marca sua presença na arena de competição entre textosevozesqueconvivemnacontrovertida formação cultural do pós-moderno.

E os tomates? A verdadeéquea escol ha polissêmicaeratambémumasimulação. Para manter o passo com o contemporâneo, urge virar suco .

\section{Bibliografia}

BAUDRILLARD, Jean. Simulacros e simulação. Lisboa: Relógio d'Água, 1991.

BERNARDET, Jean-Claude. "A crueldade irônica: a nova fórmula de violência no cinema dos anos 90". In: Imagens, 2, Campinas: Unicamp, 1994.

COOK, David A. A history of narrative film. Nova lorque: Norton, Za. ed., 1990. 
DAWSON, Jeff. Quentin Tarantino: the cinema of cool. Nova Iorque: Applause, 1995.

DELEUZE, Gilles e GUATTARI, Félix. M il mesetas: capitalismo y esquizofrenia. Valência: Pretextos, 1988.

DELGAD0, Francisco; PAYAN, Miguel Juan; UCEDA, Jacinto. Quentin Tarantino. Madrid: Ediciones JC, 1995.

JAMESON, Fredric. Espaço e imagem: teorias do pós-moderno e outros ensaios. Rio de Janeiro: UFRJ, 1994.

SHAVIRO, Steven. The cinematic body. Minneapolis: University of Minnesota Press, 1993.

TARANTINO, Quentin. Pulp Fiction. Nova lorque: Miramax Books, 1994. 